\title{
Innate immune responses in hepatitis B virus (HBV) infection
}

\author{
Aurelia Busca $^{1 *}$ and Ashok Kumar ${ }^{2}$
}

\begin{abstract}
Hepatitis B virus (HBV) infection has a low rate of chronicity compared to HCV infection, but chronic liver inflammation can evolve to life threatening complications. Experimental data from HBV infected chimpanzees and HBV transgenic mice have indicated that cytotoxic T cells are the main cell type responsible for inhibition of viral replication, but also for hepatocyte lysis during chronic HBV infection. Their lower activation and impaired function in later stages of infection was suggested as a possible mechanism that allowed for low levels of viral replication. The lack of an interferon response in these models also indicated the importance of adaptive immunity in clearing the infection. Increased knowledge of the signalling pathways and pathogen associated molecular patterns that govern activation of innate immunity in the early stages of viral infections in general has led to a re-evaluation of the innate immune system in HBV infection. Numerous studies have shown that HBV employs active strategies to evade innate immune responses and induce immunosuppression. Some of the immune components targeted by HBV include dendritic cells, natural killer cells, T regulatory cells and signalling pathways of the interferon response. This review will present the current understanding of innate immunity in HBV infection and of the challenges associated with clearing of the HBV infection.
\end{abstract}

Keywords: HBV, Innate immunity, Cytokines, Interferon response, TLRs, RIG-I

\section{Review} Introduction

Hepatitis B virus (HBV) is a noncytopathic, hepatotropic virus of the Hepadnaviridae family that causes variable degrees of liver disease in humans. Infection with HBV can be either acute or chronic; while adult infections have a relatively low rate of chronicity (around 5\%), neonatal infections usually have a high persistence rate [1]. Chronic infection is mostly asymptomatic, but HBV carriers are at risk of developing life threatening cirrhosis and later on hepatic carcinoma [2]. Despite the availability of a prophylactic vaccine, $\mathrm{HBV}$ is estimated to infect around 400 million people worldwide, with endemic areas is Asia and Africa.

HBV replication itself is not directly cytotoxic to cells, as seen in the large numbers of asymptomatic HBV carriers who have minimal liver injury, despite ongoing intrahepatic replication of the virus. The long-term aim in the treatment

\footnotetext{
* Correspondence: abusca@toh.on.ca

'Departments of Pathology and Laboratory Medicine, University of Ottawa, 451 Smyth Road, Ottawa, Ontario K1H 8M5, Canada

Full list of author information is available at the end of the article
}

of these patients is to prevent the development of cirrhosis and hepatocellular carcinoma [3]. The immune responses to HBV antigens are responsible both for viral clearance during acute infection and for disease pathogenesis. In infected humans, viral clearance follows the development of a vigorous immune response associated with acute, self-limited inflammatory liver disease (acute viral hepatitis). Immune responses involved in viral clearance comprise both humoral and cellular immunity. Majorhistocompatibility-complex (MHC) class II-restricted, $\mathrm{CD} 4+$ helper $\mathrm{T}$ cells contribute to generation of antibodies against viral envelope antigens that clear circulating virus particles. MHC class I-restricted, CD8+ cytotoxic T lymphocytes eliminate infected cells [4].

Experimental approaches to HBV pathogenesis are hampered because the host range of HBV is limited to man and chimpanzees. The functional receptor for HBV has recently been identified as sodium taurocholate cotransporting polypeptide (NTCP), a molecule implicated in bile salts transport [5]. A lot of experimental data has come from studies with hepatitis B virus transgenic mice that harbour viral antigens and replication-competent viral genomes in 
the liver. These mice harbour HBV genes in their germline DNA, therefore they are tolerant to HBV infection and do not develop significant liver injury despite high levels of replication [6]. These studies have shown the importance of cytotoxic CD8+ lymphocytes (CTLs) in controlling viral replication, as adoptively transferred virus-specific CTLs can abolish HBV gene expression and replication in the liver of $\mathrm{HBV}$ transgenic mice by causing acute liver injury [7]. Moreover, transgenic mouse studies have shown that liver disease has an immunological basis rather than being virus mediated, with CTLs also playing a central part in this process [8].

One way to overcome the inherent tolerance of HBVtransgenic mice to viral antigens was to use human hepatocyte chimeric mice, where human hepatocytes repopulated the liver of UPA/SCID mice, making it susceptible to HBV infection [9]. This model is a valuable tool for studying viral mutants and various therapeutic agents; however, the lack of human immune cells also limits the study of inflammation and immunity.

Earlier studies in animal models failed to detect innate immune responses in acute stages of HBV infection, which led to a general consensus that HBV doesn't induce innate immunity during natural infection. Despite of the development of a successful prophylactic vaccine, a lot of immunpathological processes remain unknown, especially with respect to chronic HBV infection. In this setting, virus-specific CD8+ $\mathrm{T}$ are present in the liver, but are impaired functionally or quantitatively so that they are unable to clear the infection and likely contribute to disease pathogenesis [10]. This has rekindled the interest in the innate immune responses and their impact on viral biology.

It is now thought that host immune responses to viral antigens and to viral replication in infected hepatocytes are the main determinants of hepatocellular injury and HBV pathogenesis. This review will focus on the determinants of innate immunity in controlling viral replication and their contribution to viral pathogenesis, with respect to both acute and chronic infection.

In general, innate immunity is important in controlling infection immediately after contact with the pathogen, in order to limit the spread of the infection and to initiate efficient development of an adaptive immune response. The innate immune system is activated by pathogens by using pattern-recognition receptors (PRRs) that recognize specific structures on pathogens, such as double-stranded RNA and bacterial wall components. The most important PRRs in viral infections are Toll-like receptors (TLRs), RNA helicases, such as retinoic acid inducible gene I (RIG-I) and melanoma differentiation associated gene 5 (MDA5), and double stranded RNA-dependent protein kinase (PKR) [11].

Of the TLRs, TLR9 detects viral DNA, TLR7 and TLR8 identify viral single-stranded RNA, while TLR3 recognizes viral double-stranded RNA [12]. Following recognition of virus associated molecular patterns by cellular PRRs, recruitment of their distinct adaptor proteins will sequentially activate signalling cascades to induce cytokine production in virus-infected cells.

The early phase of viral infections is mainly characterized by the production of cytokines, type 1 interferon (IFN)- $\alpha / \beta$, and the activation of natural killer (NK) cells. Production of type 1 IFNs can be triggered directly by virus replication through cellular mechanisms that detect the presence of viral RNA or DNA. The main sources of IFN- $\alpha / \beta$ are infected cells and plasmacytoid dendritic cells, whereas IFN- $\gamma$ is produced primarily by NK and NKT cells [13].

\section{Interferon response}

Earlier studies have evaluated whether HBV has the ability to stimulate the interferon pathway of the innate immune response during the early stage of infection. Data from patients and animal models have shown that there is a delay between HBV inoculation and efficient replication. Both HBV-DNA and HBV antigens become detectable around 5 weeks post-infection, after which viral titers have a logarithmic expansion phase and HBV infects most hepatocytes $[14,15]$. While it is tempting to speculate that this initial lag of replication is a result of efficient control of the virus by the innate immune response, animal studies have indicated that this is not the case, but rather that somehow the virus manages to evade being recognized. In contrast to the immune response in HCV infection, where expression of a large number of IFNregulated genes was rapidly induced in the liver of $\mathrm{HCV}$ infected chimpanzees [16], the same group has shown that HBV did not cause any change in genes associated with innate immune responses during acute HBV infection of chimpanzees [17]. The authors concluded that HBV did not induce an intrahepatic innate immune response that could be detected in the infected animals because it acts like a stealth virus early in infection, remaining undetected and spreading until the onset of the adaptive immune response several weeks later. However, the mechanisms by which HBV accomplishes this task are less understood.

Interestingly, HBV replication is sensitive to the suppressive effects of interferons in studies using the transgenic mouse model or hepatoma cell lines. HBV was shown to replicate in IFN $\gamma \mathrm{KO}$ and IFN $\alpha / \beta$ receptor $\mathrm{KO}$ mice at levels higher than those observed in control mice, implying that baseline levels of these cytokines control HBV replication in the absence of inflammation [18]. Also, expression of adaptor proteins TRIF and MyD88 (TLR adaptor proteins) and of IPS-1 (RIG-I/MDA5 adaptor protein) in human hepatoma cells was enough to limit HBV replication by reducing the steady-state levels of viral mRNAs, in a manner dependent on NF-kB transcription factor [19]. The 
importance of TLR receptor signalling in controlling HBV replication was confirmed in another study showing that a single intravenous injection of ligands specific for TLR3, TLR4, TLR5, TLR7, and TLR9 was efficient to inhibit HBV replication in a noncytolytical and IFN $\alpha / \beta$ dependent manner in HBV transgenic mice [20].

Another characteristic of the interferon response in HBV infection is that CD8+ T cells seem to control the viral replication through an IFN- $\gamma$ dependent mechanism rather than direct cell killing of infected hepatocytes [15]. The importance of noncytolytic $\mathrm{T}$ cell functions was shown in a study where the onset of viral clearance in HBV infected chimpanzees was tightly associated with the appearance of virus-specific $\mathrm{T}$ cells and mRNA in the liver, before the onset of hepatocyte destruction and clinical hepatitis [21]. These results suggest that direct cytological cell killing and IFN- $\gamma$ secretion are functionally distinct mechanisms of CD8 $+\mathrm{T}$ cells that account for control of hepatocyte destruction and viral replication, respectively.

\section{Cytokines}

Other cytokines have also been reported to control HBV replication in the transgenic mouse model, including interleukin 12 (IL-12) [22] and IL-18 [23], the effect being mediated by induction of IFN- $\gamma$ and IFN $\alpha / \beta$ respectively. Injection of $\mathrm{HBV}$ transgenic mice with CD40 ligand to induce maturation of antigen presenting cells lead to recruitment of macrophages, dendritic cells and NK cells to the liver and induced secretion of TNF- $\alpha$, IFN- $\gamma$, and IFN $\alpha / \beta$, which ultimately resulted in inhibition of HBV replication [24]. In a primary human hepatocyte model, Hosel et al. showed that briefly after infection, liver macrophages recognize HBV and induce production of TNF- $\alpha$, IL-6, IL8 and IL-1 $\beta$. However, the ability to control viral replication was attributed to IL-6 via NF-kB activation [25].

Another major antiviral cytokine is TNF- $\alpha$, which was initially shown in HBV chimpanzee model to contribute to the antiviral effects of CTLs alongside IFN- $\gamma$, although initially the source of cytokines was unknown [7]. In the HBV transgenic mouse model, TNF- $\alpha$ was secreted by antigen presenting cells following activation as part of the inflammatory cascade during acute infection [24]. Non-parenchymal liver cells like Kupfer macrophages and liver sinusoidal endothelial cells are also part of the innate immune response due to their ability to respond to TLR signalling by producing various cytokines, including TNF- $\alpha$ and IFN- $\beta$ [26]. A recent report has also shown that TNF- $\alpha$ and IL- $1 \beta$ can restrict HBV replication via activation of the NF- $\kappa B$ signaling pathway [27]. Early elevation of IL-10 and IP-10 has also been linked with better outcome during HBV vaccination [28].

Taken together, these results suggest the existence of a functional innate antiviral mechanism in hepatocytes that is associated with favourable outcome in both acute and chronic infections. Its activation under certain conditions may also be used for therapeutic purposes. Activation of innate immunity to induce interferon production but not killing of infected hepatocytes may also represent a new strategy for the treatment of chronic HBV infection, in the absence of cytological cell death associated with the activation of $\mathrm{CD} 8+\mathrm{T}$ cells.

\section{Dendritic cells}

DCs are major players in immune responses, due to their ability to process foreign antigens and present them to effector cells. The presence of HBV or HBsAg during cytokine induced maturation of dendritic cells resulted in a more tolerogenic phenotype, as shown by a decreased Tcell stimulatory capacity [29]. Other recently reported targets for $\mathrm{HBV}$ are plasmacytoid DCs (pDCs), which are major components of the antiviral immune response, due to their ability to secrete type 1 IFNs. However, HBV did not activate human $\mathrm{pDC}$ in vitro, but HBV virions and HBsAg were able to abrogate TLR7- and 9-induced IFN $\alpha$ gene transcription by direct binding TLR9-triggered $\mathrm{pDC}$ [30]. Also, TLR9-activated pDCs from HBV infected patients were impaired in their ability to induce cytolytic activity of NK cells [31]. These studies indicate that the virus exerts an immune regulatory effect that may directly contribute to its persistence during chronic infection.

\section{T regulatory cells}

The immuno-modulatory properties of HBV are also reinforced by studies that show changes in the $\mathrm{T}$ regulatory cells (Tregs) population in HBV chronically infected patients. CD4 + CD25+ Tregs normally maintain immune tolerance against self and foreign antigens, due to their ability to produce IL-10 and TGF- $\beta$. During chronic HBV infection they seem to have a deleterious effect, because they increase in number compared to acute infection or healthy controls and this increase correlates with the viral load, suggesting a direct effect on viral replication [32,33]. Generation of Tregs is also a mechanism by which pDCs contribute to immunological tolerance in healthy individuals [34]. This effect also contributes to the immune suppression that characterizes chronic infection, since pDCs from patients with chronic HBV infection were able to generate a higher proportion of Tregs compared to healthy controls [35].

Moreover, Tregs were capable of suppressing the proliferation and IFN- $\gamma$ production of autologous peripheral blood mononuclear cells mediated by HBV antigen in vitro [36], and increased numbers of Tregs were found in the peripheral blood of patients with HBV related liver failure [37], suggesting that they play an active role in the strategy employed by HBV to downregulate effector immune responses. 
Other evidence to support active immunosuppressive strategies employed by HBV includes its ability to affect the production of IL-10, a cytokine with known immunosuppressive effects. HBcAg was able to induce significantly higher IL-10 levels in peripheral blood mononuclear cells from patients with chronic HBV infection compared to those from healthy controls [38].

\section{Monocytes, natural killer cells and NK T cells}

In this setting of decreased activation of cytotoxic $\mathrm{T}$ cells, there is a continuous stimulation of other cell types that may explain the persistence of chronic infection and subsequent liver inflammation that characterize chronic HBV infection. The mechanism of chronic inflammation involves recruitment of various cell types of the innate immune system, including monocytes/macrophages and NK cells [39]. Non-classical proinflammatory monocytes of the $\mathrm{CD} 14^{\text {low }} \mathrm{CD} 16^{+}$phenotype have increased secretory functions and the ability promote fibrosis in other inflammatory diseases and infections [40]. Their expression is increased in both the peripheral blood and liver of patients with chronic HBV infection, where they positively correlate with liver inflammatory damage [41,42], suggesting their active role in this process.

The lack of type 1 IFN responses in the setting of in vivo infection seems surprising, given the fact that the majority of infected individuals are able to resolve the infection. This indicates that the viral replication may be controlled by other arms of the innate immune system.

Natural killer cells (NK cells) are the main effector population involved in innate immune responses to viral infections. They exert antiviral activity through direct cytotoxic effect or through the production of immunoregulatory cytokines (IFN- $\gamma$, TNF- $\alpha$, TGF- $\beta$, IL-10, etc). They are identified by flow cytometry by the expression of CD56 and lack of $\mathrm{T}$ cells marker CD3. CD56+ NK cells also express the FcyIII receptor CD16, which allows them to mediate antibody-dependent cell-mediated cytotoxicity [43]. NKT cells comprise a $\mathrm{T}$ cell subpopulation characterized by expression of surface markers of NK cells together with a $\mathrm{T}$ cell receptor that recognizes glycolipids associated with MHC class I-like CD1 molecules [44].

Accumulating evidence indicates that NK cells are major determinants of the clinical outcome following HBV infection. A study performed on two seronegative blood donors who became positive for HBsAg and HBV DNA without evidence of liver pathology, indicating successful containment of infection, were monitored throughout early stages of infection. Their results indicate an early activation of human innate immune system consisting of $\mathrm{CD} 56^{+} \mathrm{CD}^{-}$ $\mathrm{NK}$ and $\mathrm{CD} 6^{+} \mathrm{CD}^{+}$NKT cells. These two cell types were promptly activated before maximal HBV DNA elevation and HBV-specific T cell responses [45]. This study suggested that early and efficient induction of innate responses control the infection by non-cytolytic mechanisms rather than by hepatocyte lysis and may also contribute to timely induction of adaptive responses. Moreover, augmentation of IFN- $\gamma$ and IL-15 producing $\mathrm{CD} 6^{+}$NK cells is also an immunomodulatory effect of pegylated - IFN- $\alpha$ treatment during chronic HBV infection [46].

These results are in contrast to those observed the chimpanzee model [17] and may reflect differences between the two hosts. Studies on NK cell function early in natural human infection are rare because the incubation period of $\mathrm{HBV}$ infection is always asymptomatic and therefore difficult to study.

In a study looking at the response of NK and NKT cells following vaccination with HBsAg, there was an increased activation and IFN- $\gamma$ production in NK and NKT cells following ex vivo incubation with recombinant HBsAg in responders to vaccination. These effects were not observed in non-responders to the vaccine, suggesting that the two cell types play an important role in the immune response following hepatitis B vaccination by also contributing to a robust adaptive immune response [47]. The ability of NKT cells to control viral replication was also confirmed in vivo. Upon activation of NKT cells with a glycolipid, HBV replication was abolished and IFN- $\alpha, \beta$ and $-\gamma$ were detected in the liver of HBV transgenic mice [48]. Moreover, these effects persisted in the absence of conventional CD4+ and CD8+ T cells [48], suggesting that the innate immune response has the potential to contain the virus during natural HBV infection.

However, activation of NK and NKT cells has also been linked to liver injury in HBV transgenic mice, due to their ability to secrete proinflammatory cytokines in the hepatic microenvironment [49]. The involvement of NK activation in liver injury was not observed in human studies. On the contrary, one study comparing NK cell function in patients with chronic HBV infection with those from chronic $\mathrm{HCV}$ infection and healthy controls showed a more pronounced functional defect in chronic HBV infection than in the other two groups [50]. One recent study showed that NK numbers and cytotoxic function are maintained in peripheral blood of patients with chronic HBV infection compared to healthy controls, but their activation and cytokine production abilities (IFN- $\gamma$ and TNF- $\alpha$ ) are impaired [51]. Overall, these studies indicate that the main function of NK and NKT cells is to limit viral replication via cytokine production rather than direct cytotoxicity and that function is compromised during chronic HBV infection, which may contribute to viral persistence.

Although the exact contribution of NK and NKT cells to chronic inflammation that characterizes chronic hepatitis $B$ is yet to be established, the current literature suggest 
that strong innate responses are associated with subsequent adaptive immune activation and control of viral replication in the absence of hepatocyte lysis. Inefficient activation of the innate pathways gives rise to a lower, but persistent proinflammatory activity that cannot clear the infection and has deleterious effects on the liver microenvirnment.

\section{Viral strategies to counteract innate immune responses}

Recent developments in our understanding of the HBV infection have shown that the virus is not just a stealth pathogen, but that it employs active mechanisms to avoid recognition by the innate immune system. This may explain previous observations on its apparent inability to be detected by PRRs.

As mentioned, RNA helicases, such as RIG-I and MDA5 are important PRRs responsible for recognition of viral RNAs produced during viral infection and they represent targets for immunosupression during HBV infection [52]. Viral evasion strategies involve targeting IFN-regulatory factors (IRF) which culminate in IFN production. HBV polymerase was reported to impair antiviral innate immune responses by inhibiting IRF activation in response to TLR3and RIG-I- induced pattern recognition receptor signalling in human hepatoma cell lines [53-55].

Other HBV proteins were shown to target adaptor proteins of the RIG-I pathway.

Regulatory HBx protein binds to beta interferon promoter stimulator 1 (IPS-1) and targets it for inactivation. The consequence of HBx binding to IPS-1 is inhibition of double-stranded DNA mediated IFN- $\beta$ activation in hepatoma cell lines [56]. Human cell lines studies have also indicated that adaptor protein mitochondrial antiviral signalling (MAVS) is another target for $\mathrm{HBx}$. By promoting degradation of MAVS, induction of IFN- $\beta$ through the RIG-I pathway is prevented [57].

Another pathway that HBV uses to attenuate the antiviral responses of innate immunity is the TLR system. TLR receptors recognize nucleic acid sequences in degraded viral particles in endosomal or lysosomal cell compartments. TLR triggering initiates signal transduction pathways that promote dendritic cell maturation, production of key cytokines such as type I IFNs and initiation of adaptive immunity [58].

TLR3- and TLR4-activated murine nonparenchymal liver cells are part of the innate immune response following infection and also possess the ability to suppress HBV replication via IFN- $\beta$ induction [59]. The same group has also shown that the virus has evolved mechanisms to counteract this effect. HBV virions or viral antigens such as HBsAg and HBeAg abrogated TLR-induced antiviral activity, by suppressing IFN- $\beta$ production and induction of IFN-stimulated genes and transcription factors like IRF-3 and NF-kB [60]. The counteractive mechanisms of HBV that prevent activation of the innate responses are summarized in Table 1.

However, the actual efficacy of these inhibitory mechanisms needs to be established in the context of an in-vivo infection model. The active inhibition of innate immunity may not be very robust, since it can be overcome by exogenous stimulation. In this respect, TLR activation was shown to control viral replication in vivo in HBV transgenic mice [20].

\section{Conclusions}

The role of innate immunity in controlling HBV replication has been neglected for a number of years due to results from studies with HBV infected animals that failed

Table 1 Summary of the mechanisms employed by HBV to counteract induction of an efficient interferon response in infected cells

\begin{tabular}{|c|c|c|c|c|}
\hline Experimental model & Mechanism & $\begin{array}{l}\text { HBV protein } \\
\text { involved }\end{array}$ & Functional outcome & Reference \\
\hline Human hepatocyte cell line & Inhibition of IRF3 & HBV polymerase & Inhibition of IFN- $\beta$ induction & {$[52]$} \\
\hline $\begin{array}{l}\text { Hepatoma cell lines, liver } \\
\text { tumor samples }\end{array}$ & MAVS degradation & $\mathrm{HBx}$ & Prevention of IFN- $\beta$ induction & {$[55]$} \\
\hline Hepatoma cell lines & $\begin{array}{l}\text { Blocking DDX3 DEAD box } \\
\text { RNA helicase }\end{array}$ & HBV polymerase & $\begin{array}{l}\text { Inhibition of IFN- } \beta \text { promoter in } \\
\text { response to RIG-I/MDA5 and TLR3 }\end{array}$ & {$[51]$} \\
\hline $\begin{array}{l}\text { Hepatoma cell lines, HBx } \\
\text { transgenic mouse }\end{array}$ & HBx binding to IPS-1 & $\mathrm{HBx}$ & Inhibition of IFN- $\beta$ induction & {$[54]$} \\
\hline Hepatoma cell lines & $\begin{array}{l}\text { Binding and inactivation of mitochondrial } \\
\text { membrane protein virus-induced } \\
\text { signalling adaptor (VISA) }\end{array}$ & $\mathrm{HBx}$ & $\begin{array}{l}\text { Inhibition of virus-triggered IRF3 } \\
\text { activation and IFN- } \beta \text { induction }\end{array}$ & {$[53]$} \\
\hline $\begin{array}{l}\text { HBV transgenic mice and hepatoma } \\
\text { cell lines }\end{array}$ & & $\begin{array}{l}\mathrm{HBsAg}, \mathrm{HBeAg} \text {, or } \mathrm{HBV} \\
\text { virions }\end{array}$ & $\begin{array}{l}\text { Suppression of TLR } 1-9 \text { induced } \\
\text { activation of IRF3, NF-KB, ERK1/2 } \\
\text { and IFN- } \beta \text { production }\end{array}$ & {$[58]$} \\
\hline $\begin{array}{l}\text { VSV infection of hepatoma cell } \\
\text { lines and monocyte-derived dendritic } \\
\text { cells from patients with HBV infection }\end{array}$ & & & $\begin{array}{l}\text { Reduced RIG-I expression and } \\
\text { IFN- } \beta \text { production }\end{array}$ & {$[50]$} \\
\hline
\end{tabular}


to detect induction of type 1 interferon responses following HBV challenge. The ability of antibody responses to HBV surface antigen to protect adults from HBV challenge also indicated the importance of adaptive immunity in controlling viral replication. However, adaptive immunity alone cannot explain the persistence of HBV during chronic infection and the immune pathogenesis that characterizes chronic hepatitis B. A better understanding of how the immune systems works has lead to a reconsideration of the role of innate immunity in HBV infection. Recent research studies mentioned in this review have shown a different image of HBV pathogenesis, with active mechanisms aimed at inactivating various components of the innate immune system. Thus, the lack of interferon responses during acute infection seems to be the result of inactivation of various signalling pathways that normally induce IFN production in other viral infection. HBx and HBV polymerase are the proteins associated most frequently with inactivation of the TLR and RIG-I pathways and ultimately with impaired IFN production. These mechanisms may constitute important factors of viral persistence during natural infection, since in vitro studies have shown that $\mathrm{HBV}$ is sensitive to antiviral properties of IFNs. During the course of infection HBV also contributes to a sustained immunosuppressive state that may favour its replication, since the number of Tregs increase as disease progresses, which also decreases the number and function of $\mathrm{HBV}$ specific $\mathrm{T}$ lymphocytes.

Other components of the innate immune system that are targeted by the virus are DCs, NK and NKT cells. Their activation during acute infection or immunization is linked to a favourable clinical outcome and subsequent robust adaptive immune responses. By disrupting innate immunity pathways early during infection, the virus also compromises the quality of adaptive immune response, in favour of its survival. The interplay between innate and adaptive immunity for successful control of HBV infection is complex and needs to be addressed in future therapeutic approaches aimed at controlling viral replication.

\section{Abbreviations}

CTLs: Cytotoxic CD8+ lymphocytes; HBV: Hepatitis B virus; HCV: Hepatitis C virus; IFN: Interferon; IL: Interleukin; MDA5: Melanoma differentiation associated gene 5; MHC: Major-histocompatibility-complex; NF-kB: Nuclear factor kappa-light-chain enhancer of activated B cells; NK cells: Natural killer cells; PRRs: Pattern-recognition receptors; PKR: Double stranded RNAdependent protein kinase; RIG-I: Retinoic acid inducible gene I; TGF- $\beta$ : Transforming growth factor beta; TL: Toll-like receptor; TNF-a: Tumor necrosis factor alpha; Treg: Regulatory $T$ cell.
}

\section{Competing interests}

The authors declare that they have no competing interests.

\section{Authors' contributions}

$A B$ wrote the review, AK edited and critically appraised the manuscript as $A B^{\prime}$ s supervisor. Both authors read and approved the final manuscript.

\section{Acknowledgements}

AB was supported by an Ontario HIV Treatment Network studentship. AK was funded through CIHR grant HOP-107542.

\section{Author details}

Departments of Pathology and Laboratory Medicine, University of Ottawa, 451 Smyth Road, Ottawa, Ontario K1H 8M5, Canada. ${ }^{2}$ Biochemistry, Microbiology and Immunology, and Infectious Disease \& Vaccine Research Centre, Research Institute, Children's Hospital of Eastern Ontario, University of Ottawa, Ottawa, Ontario, Canada.

Received: 2 November 2013 Accepted: 4 February 2014

Published: 7 February 2014

\section{References}

1. McMahon BJ: Natural history of chronic hepatitis B. Clin Liver Dis 2010, 14(3):381-396.

2. Yuen MF, Lai CL: Treatment of chronic hepatitis B. Lancet Infect Dis 2001, 1(4):232-241.

3. Pramoolsinsup C: Management of viral hepatitis B. J Gastroenterol Hepatol 2002, 17(Suppl):S125-S145.

4. Chisari FV, Isogawa M, Wieland SF: Pathogenesis of hepatitis B virus infection. Pathol Biol (Paris) 2010, 58(4):258-266.

5. Yan $\mathrm{H}$, Zhong G, Xu G, He W, Jing Z, Gao Z, Huang Y, Qi Y, Peng B, Wang H, Fu L, Song M, Chen P, Gao W, Ren B, Sun Y, Cai T, Feng X, Sui J, Li W: Sodium taurocholate cotransporting polypeptide is a functional receptor for human hepatitis B and D virus. Elife 2012, 1:e00049.

6. Guidotti LG, Matzke B, Schaller H, Chisari FV: High-level hepatitis B virus replication in transgenic mice. J Virol 1995, 69(10):6158-6169.

7. Guidotti LG, Ishikawa T, Hobbs MV, Matzke B, Schreiber R, Chisari FV: Intracellular inactivation of the hepatitis B virus by cytotoxic $T$ lymphocytes. Immunity 1996, 4(1):25-36.

8. Chisari FV: Hepatitis B virus transgenic mice: models of viral immunobiology and pathogenesis. Curr Top Microbiol Immunol 1996, 206:149-173.

9. Tsuge M, Hiraga N, Takaishi H, Noguchi C, Oga H, Imamura M, Takahashi S, Iwao E, Fujimoto Y, Ochi H, Chayama K, Tateno C, Yoshizato K: Infection of human hepatocyte chimeric mouse with genetically engineered hepatitis B virus. Hepatology 2005, 42(5):1046-1054.

10. Maini MK, Boni C, Lee CK, Larrubia JR, Reignat S, Ogg GS, King AS, Herberg J, Gilson R, Alisa A, Williams R, Vergani D, Naoumov NV, Ferrari C, Bertoletti A: The role of virus-specific CD8(+) cells in liver damage and viral control during persistent hepatitis B virus infection. J Exp Med 2000, 191(8):1269-1280.

11. Thompson AJ, Locarnini SA: Toll-like receptors, RIG-I-like RNA helicases and the antiviral innate immune response. Immunol Cell Biol 2007, 85(6):435-445.

12. Kawai $T$, Akira S: Antiviral signaling through pattern recognition receptors. J Biochem 2007, 141(2):137-145.

13. Katze $M G, H e Y$, Gale M Jr: Viruses and interferon: a fight for supremacy. Nat Rev Immunol 2002, 2(9):675-687.

14. Fong TL, Di Bisceglie AM, Biswas R, Waggoner JG, Wilson L, Claggett J, Hoofnagle JH: High levels of viral replication during acute hepatitis B infection predict progression to chronicity. J Med Virol 1994, 43(2):155-158.

15. Guidotti LG, Rochford R, Chung J, Shapiro M, Purcell R, Chisari FV. Viral clearance without destruction of infected cells during acute HBV infection. Science 1999, 284(5415):825-829.

16. Su Al, Pezacki JP, Wodicka L, Brideau AD, Supekova L, Thimme R, Wieland S, Bukh J, Purcell RH, Schultz PG, Chisari FV: Genomic analysis of the host response to hepatitis C virus infection. Proc Natl Acad Sci U S A 2002, 99(24):15669-15674.

17. Wieland S, Thimme R, Purcell RH, Chisari FV: Genomic analysis of the host response to hepatitis B virus infection. Proc Natl Acad Sci U S A 2004 101(17):6669-6674

18. McClary H, Koch R, Chisari FV, Guidotti LG: Relative sensitivity of hepatitis $B$ virus and other hepatotropic viruses to the antiviral effects of cytokines. J Virol 2000, 74(5):2255-2264.

19. Guo H, Jiang D, Ma D, Chang J, Dougherty AM, Cuconati A, Block TM, Guo JT: Activation of pattern recognition receptor-mediated innate immunity inhibits the replication of hepatitis B virus in human hepatocyte-derived cells. J Virol 2009, 83(2):847-858. 
20. Isogawa M, Robek MD, Furuichi Y, Chisari FV: Toll-like receptor signaling inhibits hepatitis B virus replication in vivo. J Virol 2005, 79(11):7269-7272

21. Thimme R, Wieland S, Steiger C, Ghrayeb J, Reimann KA, Purcell RH, Chisari FV CD8(+) T cells mediate viral clearance and disease pathogenesis during acute hepatitis B virus infection. J Virol 2003, 77(1):68-76.

22. Cavanaugh VJ, Guidotti LG, Chisari FV: Interleukin-12 inhibits hepatitis B virus replication in transgenic mice. J Virol 1997, 71(4):3236-3243.

23. Kimura K, Kakimi K, Wieland S, Guidotti LG, Chisari FV: Interleukin-18 inhibits hepatitis $B$ virus replication in the livers of transgenic mice. J Virol 2002, 76(21):10702-10707.

24. Kimura K, Kakimi K, Wieland S, Guidotti LG, Chisari FV: Activated intrahepatic antigen-presenting cells inhibit hepatitis $B$ virus replication in the liver of transgenic mice. J Immunol 2002, 169(9):5188-5195.

25. Hosel M, Quasdorff M, Wiegmann K, Webb D, Zedler U, Broxtermann M, Tedjokusumo R, Esser K, Arzberger S, Kirschning CJ, Langenkamp A, Falk C, Buning $\mathrm{H}$, Rose-John S, Protzer U: Not interferon, but interleukin-6 controls early gene expression in hepatitis B virus infection. Hepatology 2009, 50(6):1773-1782.

26. Wu J, Meng Z, Jiang M, Zhang E, Trippler M, Broering R, Bucchi A, Krux F, Dittmer U, Yang D, Roggendorf M, Gerken G, Lu M, Schlaak JF: Toll-like receptor-induced innate immune responses in non-parenchymal liver cells are cell type-specific. Immunology 2010, 129(3):363-374.

27. Watashi K, Liang G, Iwamoto M, Marusawa H, Uchida N, Daito T, Kitamura K, Muramatsu M, Ohashi H, Kiyohara T, Suzuki R, Li J, Tong S, Tanaka Y, Murata K, Aizaki H, Wakita T: Interleukin-1 and tumor necrosis factor-alpha trigger restriction of hepatitis $B$ virus infection via a cytidine deaminase AID. J Biol Chem 2013, 288(44):31715.

28. Keating SM, Heitman JD, Wu S, Deng X, Stramer SL, Kuhns MC Mullen C, Norris PJ, Busch MP: Cytokine and chemokine responses in the acute phase of hepatitis $B$ virus replication in naive and previously vaccinated blood and plasma donors. J Infect Dis 2013: [Epub ahead of print]

29. Op den Brouw ML, Binda RS, van Roosmalen MH, Protzer U, Janssen HL, van der Molen RG, Woltman AM: Hepatitis B virus surface antigen impairs myeloid dendritic cell function: a possible immune escape mechanism of hepatitis B virus. Immunology 2009, 126(2):280-289.

30. Woltman AM, Op den Brouw ML, Biesta PJ, Shi CC, Janssen HL: Hepatitis B virus lacks immune activating capacity, but actively inhibits plasmacytoid dendritic cell function. PLoS One 2011, 6(1):e15324.

31. Martinet J, Dufeu-Duchesne T, Bruder Costa J, Larrat S, Marlu A, Leroy V, Plumas J, Aspord C: Altered functions of plasmacytoid dendritic cells and reduced cytolytic activity of natural killer cells in patients with chronic HBV infection. Gastroenterology 2012, 143(6):1586-1596. e8

32. Xu D, Fu J, Jin L, Zhang H, Zhou C, Zou Z, Zhao JM, Zhang B, Shi M, Ding X, Tang Z, Fu YX, Wang FS: Circulating and liver resident CD4 + CD25+ regulatory $T$ cells actively influence the antiviral immune response and disease progression in patients with hepatitis B. J Immunol 2006, 177(1):739-747.

33. Stoop JN, van der Molen RG, Baan CC, van der Laan $\sqcup$, Kuipers EJ, Kusters JG, Janssen HL: Regulatory T cells contribute to the impaired immune response in patients with chronic hepatitis B virus infection. Hepatology 2005, 41(4):771-778

34. Gilliet M, Liu YJ: Human plasmacytoid-derived dendritic cells and the induction of T-regulatory cells. Hum Immunol 2002, 63(12):1149-1155.

35. Hong J, Gong ZJ: Human plasmacytoid dendritic cells from patients with chronic hepatitis $B$ virus infection induce the generation of a higher proportion of CD4(+) and CD25(+) regulatory T cells compared with healthy patients. Hepatol Res 2008, 38(4):362-373.

36. Peng G, Li S, Wu W, Sun Z, Chen Y, Chen Z: Circulating CD4+ CD25+ regulatory $\mathrm{T}$ cells correlate with chronic hepatitis $\mathrm{B}$ infection. Immunology 2008, 123(1):57-65.

37. Dong $X$, Gong Y, Zeng H, Hao Y, Wang X, Hou J, Wang J, Li J, Zhu Y, Liu H, Han J, Zhou H, Shen L, Gao T, Zhou T, Yang S, Li S, Chen Y, Meng Q, Li H: Imbalance between circulating $\mathrm{CD} 4(+)$ regulatory $\mathrm{T}$ and conventional $\mathrm{T}$ lymphocytes in patients with HBV-related acute-on-chronic liver failure. Liver Int 2013, 33(10):1517-1526.

38. Hyodo N, Nakamura I, Imawari M: Hepatitis B core antigen stimulates interleukin-10 secretion by both $T$ cells and monocytes from peripheral blood of patients with chronic hepatitis B virus infection. Clin Exp Immunol 2004, 135(3):462-466.
39. Karlmark KR, Wasmuth HE, Trautwein C, Tacke F: Chemokine-directed immune cell infiltration in acute and chronic liver disease. Expert Rev Gastroenterol Hepatol 2008, 2(2):233-242

40. Ziegler-Heitbrock L: The CD14+ CD16+ blood monocytes: their role in infection and inflammation. J Leukoc Biol 2007, 81(3):584-592.

41. Zhang JY, Zou ZS, Huang A, Zhang Z, Fu JL, Xu XS, Chen LM, Li BS, Wang FS: Hyper-activated pro-inflammatory CD16 monocytes correlate with the severity of liver injury and fibrosis in patients with chronic hepatitis B. PLoS One 2011, 6(3):e17484.

42. Zimmermann HW, Seidler S, Nattermann J, Gassler N, Hellerbrand C Zernecke A, Tischendorf JJ, Luedde T, Weiskirchen R, Trautwein C, Tacke F: Functional contribution of elevated circulating and hepatic non-classical CD14CD16 monocytes to inflammation and human liver fibrosis. PLoS One 2010, 5(6):e11049.

43. Gregoire C, Chasson L, Luci C, Tomasello E, Geissmann F, Vivier E, Walzer T: The trafficking of natural killer cells. Immunol Rev 2007, 220:169-182.

44. Seaman WE: Natural killer cells and natural killer T cells. Arthritis Rheum 2000, 43(6):1204-1217

45. Fisicaro P, Valdatta C, Boni C, Massari M, Mori C, Zerbini A, Orlandini A Sacchelli L, Missale G, Ferrari C: Early kinetics of innate and adaptive immune responses during hepatitis B virus infection. Gut 2009, 58(7):974-982

46. Micco L, Peppa D, Loggi E, Schurich A, Jefferson L, Cursaro C, Panno AM, Bernardi M, Brander C, Bihl F, Andreone P, Maini MK: Differential boosting of innate and adaptive antiviral responses during pegylated-interferonalpha therapy of chronic hepatitis B. J Hepatol 2013, 58(2):225-233.

47. Albarran B, Goncalves L, Salmen S, Borges L, Fields H, Soyano A, Montes H, Berrueta L: Profiles of NK, NKT cell activation and cytokine production following vaccination against hepatitis B. APMIS 2005, 113(7-8):526-535.

48. Kakimi K, Guidotti LG, Koezuka Y, Chisari FV: Natural killer T cell activation inhibits hepatitis B virus replication in vivo. J Exp Med 2000, 192(7):921-930.

49. Trobonjaca Z, Kroger A, Stober D, Leithauser F, Moller P, Hauser H, Schirmbeck R, Reimann J: Activating immunity in the liver. II. IFN-beta attenuates NK cell-dependent liver injury triggered by liver NKT cell activation. J Immunol 2002, 168(8):3763-3770.

50. Oliviero B, Varchetta S, Paudice E, Michelone G, Zaramella M, Mavilio D, De Filippi F, Bruno S, Mondelli MU: Natural killer cell functional dichotomy in chronic hepatitis $B$ and chronic hepatitis $C$ virus infections. Gastroenterology 2009, 137(3):1151-1160. 1160.e1-7.

51. Tjwa ET, van Oord GW, Hegmans JP, Janssen HL, Woltman AM: Viral load reduction improves activation and function of natural killer cells in patients with chronic hepatitis B. J Hepatol 2011, 54(2):209-218.

52. Zhao G, An B, Zhou H, Wang H, Xu Y, Xiang X, Dong Z, An F, Yu D, Wang W, Bao S, Xie Q: Impairment of the retinoic acid-inducible gene-I-IFN-beta signaling pathway in chronic hepatitis B virus infection. Int J Mol Med 2012, 30(6):1498-1504

53. Wang $H$, Ryu WS: Hepatitis B virus polymerase blocks pattern recognition receptor signaling via interaction with DDX3: implications for immune evasion. PLoS Pathog 2010, 6(7):e1000986.

54. Yu S, Chen J, Wu M, Chen H, Kato N, Yuan Z: Hepatitis B virus polymerase inhibits RIG-I- and Toll-like receptor 3-mediated beta interferon induction in human hepatocytes through interference with interferon regulatory factor 3 activation and dampening of the interaction between TBK1/ IKKepsilon and DDX3. J Gen Virol 2010, 91(Pt 8):2080-2090.

55. Wang $X$, Li Y, Mao A, Li C, Li Y, Tien P: Hepatitis B virus $X$ protein suppresses virus-triggered IRF3 activation and IFN-beta induction by disrupting the VISA-associated complex. Cell Mol Immunol 2010, 7(5):341-348.

56. Kumar M, Jung SY, Hodgson AJ, Madden CR, Qin J, Slagle BL: Hepatitis B virus regulatory $\mathrm{HBx}$ protein binds to adaptor protein IPS-1 and inhibits the activation of beta interferon. J Virol 2011, 85(2):987-995.

57. Wei C, Ni C, Song T, Liu Y, Yang X, Zheng Z, Jia Y, Yuan Y, Guan K, Xu Y, Cheng $X$, Zhang $Y$, Yang $X$, Wang $Y$, Wen $C$, Wu Q, Shi W, Zhong H: The hepatitis $B$ virus $X$ protein disrupts innate immunity by downregulating mitochondrial antiviral signaling protein. $J$ Immunol 2010, 185(2):1158-1168.

58. Barton GM: Viral recognition by Toll-like receptors. Semin Immunol 2007, 19(1):33-40

59. Wu J, Lu M, Meng Z, Trippler M, Broering R, Szczeponek A, Krux F, Dittmer U, Roggendorf M, Gerken G, Schlaak JF: Toll-like receptor-mediated control of 
HBV replication by nonparenchymal liver cells in mice. Hepatology 2007, 46(6):1769-1778.

60. Wu J, Meng Z, Jiang M, Pei R, Trippler M, Broering R, Bucchi A, Sowa JP, Dittmer U, Yang D, Roggendorf M, Gerken G, Lu M, Schlaak JF: Hepatitis B virus suppresses toll-like receptor-mediated innate immune responses in murine parenchymal and nonparenchymal liver cells. Hepatology 2009, 49(4):1132-1140.

doi:10.1186/1743-422X-11-22

Cite this article as: Busca and Kumar: Innate immune responses in

hepatitis B virus (HBV) infection. Virology Journal 2014 11:22.

\section{Submit your next manuscript to BioMed Central and take full advantage of:}

- Convenient online submission

- Thorough peer review

- No space constraints or color figure charges

- Immediate publication on acceptance

- Inclusion in PubMed, CAS, Scopus and Google Scholar

- Research which is freely available for redistribution 